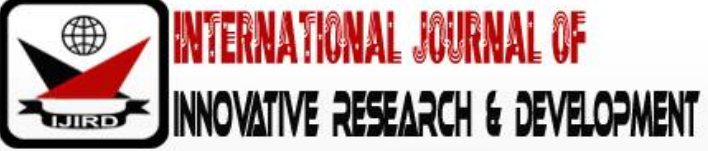

ISSN 2278 - 0211 (Online)

\section{Factors Influencing Wild Animals Poaching In Ruvuma Region Tanzania}

\author{
Bahati Golyama \\ Student, Open University of Tanzania, Tanzania \\ Jerome Metody Nilahi \\ Student, Open University of Tanzania, Tanzania
}

\begin{abstract}
:
This research analyzed the influence of facilitating condition (FA) on intentional wild animals' poaching in Ruvuma Region Tanzania. The study employed both qualitative whereby participant field observation was being a used and quantitative research method whereby survey design was employed. The sample size of the study was 266 respondents. Stratified sampling technique was applied to portray the study subjects. Data analysis was done quantitatively using structural equation modelling. The findings of the study indicate that, facilitating condition found with positive but insignificant influence on intentional wild animals poaching. In addition, all attributes facilitating condition indicated positive and significant influence on intentional wild animals poaching in Ruvuma Regional Tanzania. The study concludes that other factors which hinder the effectiveness of facilitation conditional on influencing intentional wild animals poaching in Ruvuma region Tanzania should be traced and be determined to include on anti-poaching activities.
\end{abstract}

Kevwords: Inadequate resources. Wildlife. Law enforcements. Influence. Wild animals. Poachina

\section{Background of the Study}

Wild animals are essential to Tanzania's economy, as it sustains millions of the country's rural population. It is also the keystone to the tourism industry-a sector that accounts for about $17 \%$ of the country's gross domestic product (GDP) and is the largest source of foreign exchange about 25\% (Kideghesho, 2016). However, unlawful taking of wildlife is a serious crisis in today's society. Even though from early 1970s some studies maintain the poaching problem has been blown out of amount and in actual fact is a minor problem (Beattie at. el., 1977). Meanwhile other studies like Gavitt (1989) and Hall (1992) advocate that wildlife law violations are a mark cant problem that required to be addressed. Some studies even have claimed it has reached a crisis level because of the volume of wildlife that is lost to this unlawful activity (Musgrave at el., 1993).This clime supported by World Wildlife Fund (WWF) report the global wild animals' population have decreased by 84\% between 1970 and 2015 due to poaching (WWF, 2015).Jackson (2013) pointed out due to social economic development, poaching of wild animals has become a source of illegal income.

Realizing the importance of wildlife in social economic,as a counter reaction against escalating wild animals poaching in March 2016,Jumanne Maghembe the then minister for Natural Resources and Tourism suspended eleven senior officials on corruption allegations for allowing hunting of 300 monkeys without a permit (Mwalimu, 2016). Furthermore participant field observation from 2000-2015 found that, the Ruvuma rangers captured 127 pieces of ivory. They also captured several kilograms of bush meat which included 202 kilograms of elephant meat,246 kilograms of Hippopotamus meat, and 149 kilograms of buffalo meat. Other items seized were one skin of zebra, 17 teeth of common warthog and three scales of pangolin.

However, inadequate resources among wildlife law enforcements are subject for discussion. Bruner et al.,(2001) advocate that poaching incidences are well detected, within the protected areas where infrastructure are not friendly for patrol roads, anti-poaching camps and wireless equipment. Meanwhile Eliason's (2011) report on comments from game wardens which reveal five major issues confronting conservation law enforcement officers: inadequate funding, low salaries, non-wildlife law enforcement duties, lack of support from the judicial court system, and changing social and political climate. On the same vain Wilfred (2010) suggests out that to combat poaching poor resource use diversification and lack of creativity constrain sustainable use of natural resources in the WMAs; consequently, their contribution to sustainable livelihoods is seriously undermined.

\section{Literature Review}

\section{1. Theoretical Literature Review}

In finding out on how inadequate resources among wildlife service person influence wild animals poaching in Ruvuma Region Tanzania, Ajzen (1991) introduced the Theory of Planned Behaviour (TPB) in predicts deliberate 
behaviour.TPB consist three components attitude, subjected norms and perceived behaviour control (facilitating conditional). Armitage (2001) commented that TPB has almost 20 years of existence, and it is proven that the theory is useful in predicting people's behaviour). From this TPB therefore, this study opted perceived behavioural control in finding how insufficient resources amongst ant-poaching argents influence wild animals poaching in Ruvuma Region Tanzania. The reason is that behaviour such as wild animals poaching can be deliberative and planned. McCleery et al. (2006) argues that, facilitating condition refers to perceived ability to successfully perform a particular behaviour, such as by possessing the necessary knowledge, resources and autonomy, and make use of control over one's life.

\subsection{Empirical Literature Review}

Baldus et al. (2004) advocate that the wildlife sub-sector has, since then, recorded a steep drop in its budgets and therefore failing to meet its conservation obligations effectively, including those of law enforcement. Budgets allocated are too low to combat commercial poaching in Tanzania. This has led in turn to equipment inadequacy to low salary and low motivation for wild animal's officers which demoralized anti- poaching activities. Minimal budget is a threat to existing manpower. On the same vain Kideghesho (2016) found that minimal budget distribution to wildlife sector cripples law enforcement activities including patrols, prosecution, investigation and intelligence. Further to minimal budget, the existing manpower and equipment are inadequate.

The most common issue wildlife rangers recognized was inadequate funding. Rangers reported time after time that the funding condition in the department was grim. The apparent lack of funding to fulfill their obligations is important because it may also add to low morale in the department Eliason (2011).Connected to the problem of inadequate funding was low pay. Salaries are not keeping up with the new demands of the job. It's tough to attract people to the profession because of the low pay but the problem is particularly acute with respect to game warden jobs. Inadequate remuneration was identified by respondents as a major impediment to recruitment and retention efforts of the organization because it adversely affects the ability of the department to attract and retain wardens Montana Fish, Wildlife, and Parks. (2011).

On the other hand, some wardens expressed frustration with the response of the justice system to wardcases of wildlife law violation and felt that some actors in the process undermined their efforts to prosecute offenders. In particular, they indicated that a great deal of time and effort may be spent building a case against a violator, only to have a judgeor prosecutor dismiss the case or go extremely lenient on the violator: Exacerbating the problem are private property laws in the state, including a state Supreme Court decision that restricts game wardens from entering private property for patrol purposes unless they have a warrant or permission from the landowner

(Rosen and Smith, 2010)

In additional, today record levels of funding are being invested in enforcement and anti-poaching measures to tackle the "war on poaching," but many species are on the path to disappearance. In some observation, increasing enforcement effort is crucial, but will ultimately prove an inadequate long-term strategy with which to conserve high-value species. This is because: regulatory approaches are being overwhelmed by the drivers of poaching and trade, financial incentives for poaching are increasing due to rising prices and growing relative poverty between areas of supply and centers of demand, and aggressive enforcement of trade controls, in particular bans, can increase profits and lead to the involvement of organized criminals with the capacity to operate even under increased enforcement effort Challender, (2011). Furthermore, it has been found that most resources dedicated to fighting the illegal wildlife trade are focused on front-line enforcement efforts and, to a lesser extent, demand reduction. Relatively few are dedicated to communityfocused initiatives. Critics posit that many more must be directed towards local communities, with some arguing that conservation law enforcement and local people need not be at odds(Duffy and Humphreys, 2014).Despite the positive and critics of resources allocation on anti-poaching activities little has been done to solve the issues of resources on antipoaching in Ruvuma region Tanzania, which needed additional analysis.

\section{Methodology}

Saunder et al (2014) define research methodology as a means of beliefs and assumptions about the development of knowledge. This study adopted pragmatism research methodology. A pragmatist believes in an external world independent of the mind and the existence of different world views and assumptions and, therefore, chooses research techniques that best suit their purpose (Creswell, 2009). Elkjaer and Simpson (2011) point out that pragmatism intended to bring together both interpretivism and positivism paradigms. Furthermore, it does this by taking into consideration theories, concepts, ideas, hypotheses and research outcomes not in an abstract form, but in terms of the roles they take part in as instruments of thought and action, and in terms of their practical consequences in specific contexts (Watson, 2011). Based that foundation, the current study adopted both quantitative and qualitative research methods.The survey questionnaires were a major source of data collection.The study population was 509and from this population, 283 respondents was selected as a sample size. Furthermoreparticipant observation as a supplement research tools, the aims was to tries to find out what life is like for an "insider" while remaining, without doubt, an "outsider" (Handwerker, 2001).The researchers visited Mbarang'andu and the other sites in Nalika, Kimbanda, Kisungule WMAs and the communities living near Ruvuma Region protected areas. The researchers observed the WMAss management interventions such as anti-poaching guard posts and habitat management projects, including water ponds within the WMAs. The area has been selected because it experiences a long range of wild animals poaching (Lotter \& Clark, 2016).Wasser et al. (2009) point out that through DNA fingerprinting shows how tusks seizures in Hong Kong and Taiwan provided further strong evidence that many tusks were poached in a relatively small area on the Tanzania and Mozambique border that includes the Selous and Niassa protected areas. Potentially, the area borders Selous Game Reserve in the East, North East and North.Likert scale was used to rate the survey questionnaire. In analysis phase, 
descriptive approach was used to ascertain the normality of the numbers, factorial analysis for authenticating the underlying constructs and structural equation model used for examining the stated hypothesis. Also, the validity and reliability issues were considered to obtain valid and reliable results. For examplecomposite reliability, convergent and discriminant validity analyzed during confirmatory factor analysis and results signify reliable and valid findings as indicated in Table3.1. As argued by Bove et al. (2009) that without conducting discriminant validity researchers cannot be certain whether the results confirm the hypothesized model. Furthermore, nomo logical validity assessed using SEM where the standardized coefficients were found being above 0.2 as suggested by (Fornell and Larcker, 1981).

\begin{tabular}{|c|c|c|c|c|c|c|c|c|c|}
\hline & CR & AVE & MSV & Mar & & AT & $\mathbf{P A}$ & SO & FC \\
\hline $\mathrm{FC}$ & 0.763 & 0.553 & 0.243 & 0.794 & 0.493 & 0.393 & 0.338 & \multicolumn{2}{|c|}{0.673} \\
\hline$\overline{\mathrm{PA}}$ & 0.696 & 0.537 & 0.287 & 0.7 & & 0.528 & 0.608 & & \\
\hline
\end{tabular}

Table 1: Composite Reliability (CR), Convergent and Discriminate Validity of Construct

Source: Reseacher (2018)

Meanwhile, reliability tested using the Cronbach's alpha $(\alpha)$ analysis and findings shown very reliable variables since the Cronbach's coefficient range from 0.0756 to 0.775 as indicated on Table 2.

\begin{tabular}{|c|c|c|}
\hline Variables & No attributes & Cronbach's Alpha \\
\hline Facilitate Condition & 5 & 0.775 \\
\hline Intentional Poaching & 5 & 0.756 \\
\hline Source: Reseacher (2018) & & \\
\hline
\end{tabular}

Table 2: Reliability of Variables

\section{Findings of the Study}

This study appraised the appropriateness of items to their underlying structure construct as recommended by Yong and Pearce (2013). Initially, the study measured sampling adequacy using Kaiser-Meyer-Olkincriterial (KMO) and Bartlett's Test of Sphericity. The assessment results had KMO 0.880 and Bartlett's Test of Sphericity was significant as indicated in Table 3. Therefore, based on KMO results in this study, it confirms that the data was adequacy for conducting analysis using exploratory factor analysis (EFA).

\begin{tabular}{|c|c|c|}
\hline Kaiser-Meyer-Olkin Measure of Sampling Adequacy. & $\mathbf{. 8 8 0}$ \\
\hline Bartlett's Test of & Approx. Chi-Square & $7.644 \mathrm{E} 3$ \\
\cline { 2 - 3 } Sphericity & $\mathrm{df}$ & 561 \\
\cline { 2 - 3 } & Sig. & .000 \\
\hline
\end{tabular}

Table 3: KMO and Bartlett's Test

Source: Reseacher (2018)

\subsection{Exploratory Factor Analysis}

Exploratory factor analysis was applied in this study to approximate the unknown structure of the data to be sure based on Tanzanian context. Under EFA all items with loading ranging from 0.4 to 0.8 were retained and those with loading less than 0.4 or above 0.8 were dropped. Facilitating condition had six items and all were retained while the regional commissioner's offices performance had twelve items six was dropped and six was retained. Items were dropped because of having weak and multiple loading which affected the model fitting. The dropped items are expressed in Table 4.

\begin{tabular}{|c|c|}
\hline Variable & Item dropped \\
\hline FC: Facilitate Condition & $\begin{array}{l}\text { FC7: Negligence } \\
\text { FC8:Ignorance }\end{array}$ \\
\hline \multicolumn{2}{|c|}{ PA1: Poaching network } \\
\hline \multicolumn{2}{|c|}{$\begin{array}{l}\text { PA: Poaching intention } \\
\text { PA2: Proximity } \\
\text { PA6: Bush meat }\end{array}$} \\
\hline
\end{tabular}

Table 4: Dropped Items on Exploratory Factor Analysis Rotated Component Matrix ${ }^{a}$ Source: Researcher, 2018

The fixed items on each construct retained are shown in Table 5.After recognized the study framework from the EFA, the next step was to perform confirmatory factor analysis (CFA). 


\begin{tabular}{|l|c|}
\hline \multicolumn{1}{|c|}{ FC: Facilitate Condition } & FC9: Inadequate resources \\
& FC10:low salary \\
& FC13:Low Motivation \\
& FC14:Climate change \\
\hline PA6: Bush meat & \\
PA: Poaching intention & PA9: Tusks \\
PA2: Firearms, snare, traps and poisoning & \\
\hline
\end{tabular}

Table 5: Definitions of Constructs and Their Measurements

Source: Researcher, 2018

\subsection{Confirmatory Factor Analysis}

Confirmatory factor analysis measurement model was developed to test for specification error and correlation between the latent variables (Steiger, 1990). In addition, a measurement model of the constructs was validated. The standardized regression weights and modification indexes that reveal high covariance between measurement errors, accompanied by high regression weights between these errors' construct and cross loading items were observed. In addition, model fit indexes were used to examine the fitness of the model after modifications. Examples of the absolute fit indices used are the goodness of fit indices (GFI), and the Chi square statistics (Bentler, 1995). In addition, adjusted for parsimony indices which were used in this study are the root mean square error of approximation (RMSEA) and adjusted goodness fit index (AGFI) (Byrne, 2013). The last indices used were the relative fit indices which are comparative fit index (CFI). On facilitating condition measurement model was specified with the following observed variable namely FC2,FC5, FC10, FC13 and FC14 for confirmatory factor analysis. Initially CFA was run using IBM Amos 20 with maximum likelihood estimate, the model fit index indicated the following indices: $\mathrm{CMIN} / \mathrm{df}=5.955, \mathrm{P}=0.00, \mathrm{GFI}=0.935, \mathrm{AGIF}=0.849, \mathrm{CFI}=$ 0.936 and RMSEA $=0$. 266. These findings showed poor fit of the model based on model fitness criteria recommended by Schumacker and Lomax (2004) and Hooper et al (2008) that a model fits well when it achieves a CMIN/ DF of 3 or less indicating an acceptable fit, CFI $>0.90$ indicates good fit), RMSEA $\varangle 0.08$ indicates acceptable fit, and GFI of at least 0.9 indicates acceptable fit. Barrett (2007) suggests that if the model is poor, it can be modified and the model retested either by adding or removing parameters to improve the fit. In addition, based on these arguments, one item deleted in order to improve the intellectual stimulation measurement model which is FC2. After deletion of FC2 then CFA was run again and the findings indicated fitness of facilitating conditions measurement model as follows: $\mathrm{CMIN} / \mathrm{df}$ ratio $=1.007, \mathrm{P}=0.1007$, GFI $=0.996$, AGFI 0.981, CFI $=1.000$ and RMSEA $=0.005$.

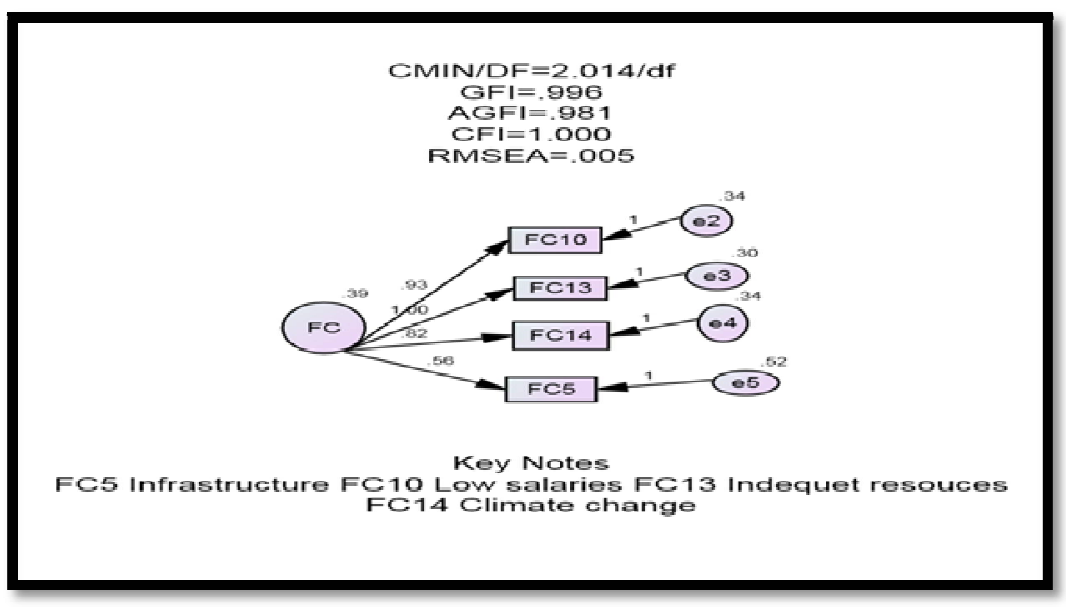

Figure 1: Facilitate Condition Measurement Model

Source: Researcher (2019)

\subsection{Measurement Model for Intentional Poaching (PA)}

At the beginning the intentional poaching variable was composed by the following items namely PA1, PA2, PA6, PA7, PA9 and PA10 for confirmatory factor analysis. Initially CFA was run using IBM Amos 20 with maximum likelihood estimate, the model fit index indicated the following indices: $\mathrm{CMIN} / \mathrm{df}=7.237, \mathrm{P}=0.00$, GFI $=0.952$, AGIF $=0.855$, CFI $=867$ and RMSEA $=0$. 153. These findings showed poor fit of the model base on model fitness criteria recommended by Schumacker and Lomax (2004) and Hooper et al. (2008) that a model fits well when it achieves a CMIN/ DF of 3 or less indicating an acceptable fit, CFI $>0.90$ indicates good fit), RMSEA $\varangle 0.08$ indicates acceptable fit, and GFI of at least 0.9 indicates acceptable fit. Barrett (2007) suggests that if the model is poor it can be modified and the model retested either by adding or removing parameters to improve the fit. In addition, based on this argument, two items were deleted in order to improve the intellectual stimulation measurement model which is PA1 and PA7. After deletion of both PA2 and PA7 then CFA was run again and the findings indicated fitness of inspirational motivation measurement model as follows; $\mathrm{CMIN} / \mathrm{df}$ ratio $=1.141, \mathrm{P}=0.320, \mathrm{GFI}=0.996$, AGFI 0.979, $\mathrm{CFI}=0.995$ and $\mathrm{RMSEA}=0.023$. 


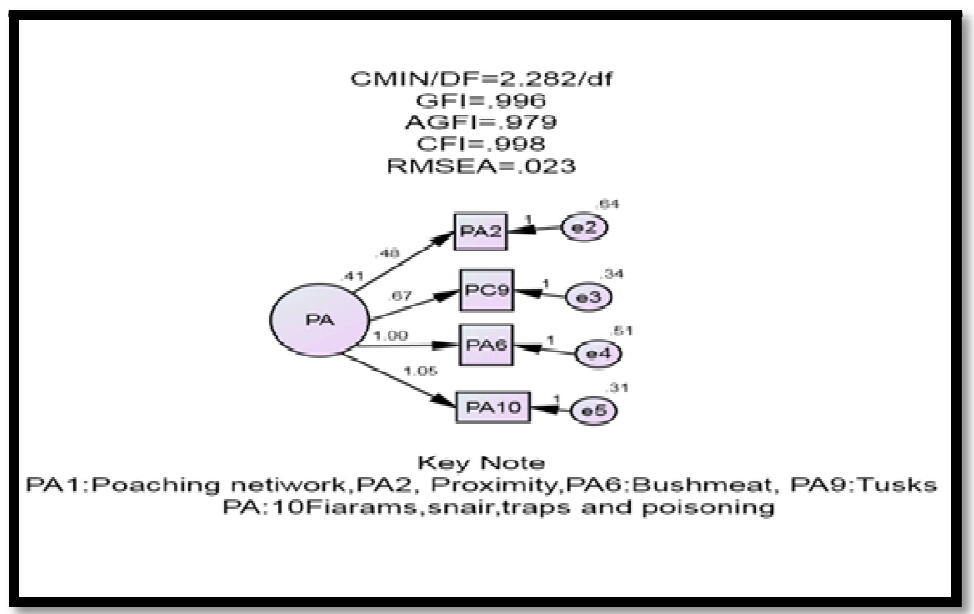

Figure 2: Intentional Poaching

Extent Source: Researcher (2019)

\subsection{Facilitate Condition}

\begin{tabular}{|c|c|c|c|c|c|}
\hline \multicolumn{2}{|c|}{} & Frequency & Percent & Valid Percent & Cumulative Percent \\
\hline \multirow{3}{*}{ Valid } & Low & 66 & 24.8 & 24.8 & 24.8 \\
\cline { 2 - 6 } & Moderate & 67 & 25.2 & 25.2 & 50.0 \\
\cline { 2 - 6 } & High & 133 & 50.0 & 50.0 & 100.0 \\
\cline { 2 - 6 } & Total & 266 & 100.0 & 100.0 & \\
\hline
\end{tabular}

Table 6

The results revealed that half of the respondents (50\%) they came to agree that facilitate condition such as infrastructure (FC5), low salaries (FC10) and climate change (FC14) contribute to wild animals poaching in Ruvuma region. Although FA has contribution to wild animals poaching yet its percentage is not strong compared to the other factors such as AT and SO. Regardless of it slow percentage but in case D from WMAs which argued that though it believed that all wild animals are government properties, "this statement is not true because some are protected with strong arms (those which are in game control areas, game reserves) while others which are in WMAs are protected by rungu (sticks with knob on the end) and bows and arrows". Baldus et al. (2004) advocate that the wildlife sub-sector has, since then, recorded a steep drop in its budgets and therefore failing to meet its conservation obligations effectively, including those of law enforcement. Further analysis was done using structural equation model in order to determine the significant influence of facilitating condition indicators on intentional wild animals poaching in Ruvuma Region Tanzania.

\subsection{Regression Weights and SRW}

\begin{tabular}{|c|c|c|c|c|c|c|c|c|c|}
\hline Path Estimate & & & Estimate & S.E. & C.R. & P & Label & SRW & Remarks \\
\hline PA & $<---$ & FC & .065 & .098 & .658 & .511 & & .058 & Not Supported \\
\hline Facilitate9 & $<---$ & FC & 1.381 & .168 & 8.200 & $* * *$ & & .751 & Supported \\
\hline Facilitate14 & $<---$ & FC & 1.000 & & & & & .576 & Supported \\
\hline Facilitate5 & $<---$ & FC & 1.512 & .185 & 8.170 & $* * *$ & & .822 & Supported \\
\hline
\end{tabular}

Table 7

Source: Researcher 2018

The path leading from FCto PC In the above table is used to examine the relationship between influences of facilitating condition on intentional wild animals poaching in Ruvuma region in Tanzania. A positive standardized path coefficient $(\gamma=0.058)$ from a path FC leading to PA in above indicates poor relationship. As argued by Chin (1998) that a standardized paths should be at least 0.2 in order to be considered useful for discussion. Comparing these results with the hypotheses, the standardized path coefficient of 0.058 seems to indicate that impact of facilitating condition on intentional wild animals poaching in Ruvuma region in Tanzania is not support. Further analysis on the significant influence of influence of facilitating condition on intentional wild animals poaching in Ruvuma region in Tanzania was done using critical ratio and significance level $p$ value. The results have yielded a critical ratio of 0.658 and $p$-value of 0.511 . As argued by Hox and Bechger (2014) that a relationship which has a yield critical ration greater than 1.96 and p-value less than 0.05 is considered significant. Comparing this study hypothesis, a critical ratio of 0.658 and p-value of 0.511 indicate insignificant factors influence on wild animals poaching in Ruvuma in Tanzania. However, individual items under facilitate condition are influence poaching, therefore generally FC holds true on supporting poaching due to the fact that it has positive influence and its items has strong positive and significant impact. 


\section{Discussion of the Findings}

\subsection{The Influence of Facilitating Condition on Wild Animal Poaching}

The present study examined the influence of facilitating condition on wild animal poaching in Ruvuma region in Tanzania. The processes involved inspecting whether facilitating condition has positive and significance influence on wild animal poaching. Exploratory and confirmatory factor analysis was used to establish the model fit items which strongly related with inspirational motivation construct. The fit items used to measure the influence of facilitating condition on wild animal poaching in Ruvuma region in Tanzania are inadequate resource, low salary and climate change.

Based on that back ground, in the current study it was hypothesized that facilitating conditions have significant influence on intentions towards wild animals poaching in Tanzania. The empirical result in chapter four of this study doesn't support the above hypothesis by yielding standardized coefficient estimate $(\gamma)$ of 0.058 , critical ration (C.R) of 0.658 and significant p-value of 0.511 . These findings present a negative and insignificant contribution of facilitating conditions on wild animals poaching in Ruvuma region in Tanzania. Chin (1998) suggested that a standardized paths coefficient $(\gamma)$ should be at least 0.2 in order to be considered significant and meaningful for discussion. This shows that the attributes which were measuring the facilitating conditions variable are not providing enough explanatory power for explaining the significant influence on wild animals poaching in Ruvuma region in Tanzania. Furthermore, the results from descriptive analysis also indicated that $50 \%$ of the respondents supported the hypotheses that facilitate conditions influence wild animals poaching in Ruvuma region in Tanzania. The result from case studies such as case A from Tunduru district that they don't have strong guns and evidence from case B shows that "lack of ecological manipulation" as facilitating wild animals poaching in Ruvuma region. On the other hand the evidence from the researcher's observations discovered that within WMAs like Kimbanda, Kisungule and Chingole, they don't have facilities such as vehicles, guns for protecting wild animals and themselves. A finding from the current study both disapproves and approves the empirical results which have been conducted in other contexts. For example, findings in this study are similar with Daigle (2001) who conducted a study in predicting illegal hunting "intentions (poaching) and Behaviour: An Application of the Theory of Planned Behaviour "findings indicated that facilitating conditions did not account for additional variance in illegal hunting (poaching) behaviour, suggesting that illegal hunting-related activities are largely not influenced by facilitate condition. This result points out that facilitating condition is not an influence on wild animals poaching. Additionally, the lack of resources, low motivation which were indicators found in facilitating conditions are also mentioned in the Theory of Planned Behaviour (TPB). Ajzen (1991) also found the said condition also lower people's actual behavioural control, consequently limiting the probability of behavioural change, regardless of the intentions. The results revealed that facilitating condition has insignificant relationship with factors influencing wild animals poaching.

Apart from the mentioned results above, these findings don't support the arguments made by Heinrich (2016) that facilitating condition significantly influences wild animals poaching Therefore, the results of the present study indicate that, facilitating condition is less meaningfully related to the wild animals poaching in Ruvuma region in Tanzania. Even though, the facilitate condition shows negative and incognisant relationship meaningful but its' attributes such as inadequate resource, low salary and climate change indicated positive and significant relationship with the intentional poaching meaning it is positive but insignificant. The present study recommends that facilitating condition will be more meaningful when other factors which were not included in the current study are combined. Participant field of ten days with rangers patrol, Rangers were well equipped, well dressed militarily, strong arms, good food and well paid. We found snares, wild animals' carcass Ten day, with District Game Officer'car, left us and returns. VGSs with one Game warden from District Game Officer' office with short gun and rifle, not well dressed, very committed to patrol and capture 4 poachers with hippo meat, snares half land cruiser. Hence, the crucial point obtain from the current study is that facilitating condition found was insignificant in influencing poaching in Ruvuma region in Tanzania. May be there are other ways that could help to explain this construct which were not included in this study. Meanwhile its attribute like inadequate resource, low salary alone cannot justify the predicting power of facilitating condition of its influence on wild animals poaching in Ruvuma region in Tanzania. Therefore, when other attributes are included and combined with inadequate resource, low salary and climate change can justify well the significant value of facilitating condition; this suggests that facilitating condition still hold true to some extent in supporting wild animals poaching in Ruvuma region in Tanzania. Participant field observation in Ruvuma region found that, within Game Reserves, Game Controlled Areas and Antipoaching NGOs. Their equipped in terms with facilities heavy arms, cars but with ought Antenna helping communication with those in patrol and in office. While in WMAs and Districts, do not having facilities neither heavy arms but they have good offices.

Based on the above point of discussion, the present study concludes by advocating that for the government to improve the existing poaching mitigation measures the is need to consider social science research findings related on factors influencing wild animals poaching. The social sciences study findings can help policy makers understand the politics, psychology, economics, and framing of conservation challenges. Since the current study findings indicated that social factors influence wild animals poaching, it advisable that policy makers together with communities living near protected areas should find short term and long term solutions to overcome social factors influence on wild animals poaching in Ruvuma region and in Tanzania at large.

\subsection{Conclusion}

The influence of facilitating conditions on intentional wild animals poaching in Ruvuma region is less. However all three attributes of facilitating conditions are positively and significantly influencing wild animals poaching in Ruvuma 
Region. Therefore, for facilitating conditions to be significant other attributes should be involved and combined with the three attributes namely inadequate resources, low salaries and climate change.

To conclude, because of the three attributes identified in this study are significant, it implies that facilitating conditions still embrace facts in influencing intentional wild animals poaching in Ruvuma region Tanzania. These would provide good ways to find mitigation measures on wild animals poaching in Ruvuma region Tanzania.

\section{Recommendations for Future Research}

This study was conducted in one country, Tanzania; it is not clear whether the results and the model validated from this study can also be relevant in other countries due to context difference. This study urges a study to be done in more than one country in order to confirm and establish more evidence which could help to give details adoption phenomenal in developing countries and match up to some unique characteristics found in each country under investigation.

On the other hand, this study was conducted in Ruvuma Region. Tanzania is blessed country with wildlife. A similar study can be conducted at forestry department, to find out whether inadequate resources are problem on protecting other wildlife in Tanzania. The future research can address the above limitations by conducting a comparative study.

The study did not use moderators; other studies cab be conducted in the Ruvuma Region by including moderating variables. The facilitating condition by the presence of moderating variable can significantly influence intentional wild animals poaching in Ruvuma Region Tanzania.

There is need to do research on TPB to find out reasons why facilitating condition does not support intentional wild animals poaching in Ruvuma Region.

\section{References}

i. Ajzen. I (1991). The theory of planned behaviour. Organization Behaviour and Human Decision Processes. 50, p179-211.

ii. Armitage, C.J. and Conner, M. (2001). Efficacy of the Theory of Planned Behaviour: A Meta-Analytic Review. British Journal of Social Psychology, 40 (4): 471-499.

iii. Baldus, R. D. 2004. Lion Conservation in Tanzania Leads to Serious Human-Lion Conflicts with a Case Study of a Man-eating Lion Killing 35 People. Tanzania Wildlife Discussion Paper 41:1-63.

iv. Beattie, K. H., Giles, R. H., \& Cowles, C. J. (1977). Lack of research in wildlife law enforcement. Wildlife Society Bulletin, 5, 170-174.

v. Bentler, P. M. (1995). EQS Structural Equations Programme Manual. Encino, CA: Multivariate Software.

vi. Bove, L. L., Pervan, S. J., Beatty, S. E., \& Shiu, E. (2009). Services Worker Role in Encouraging Customers Organisational Citizenship Behaviour. Journal of Business Research, Vo. 62. No. 7 PP 698 - 705.

vii. Buyrne, B. M. (2013). Structural Equation Modelling with Amos: Basic Concept, Application, and Programming. Routledge

viii. Challender, D.W.S. (2011) Asian pangolins: increasing affluence driving hunting pressure. TRAFFIC Bull., 23, 9293

ix. $\quad$ Chase, M. J.; Schlossberg, S.; Griffin, C. R.; Bouch'e, P. J.;Djene, S. W.; Elkan, P. W.; Ferreira, S.; Grossman, F.; Kohi,E. M.; Landen, K.; et al. (2016) Continent-wide survey reveals massive decline in african savannah elephants. PeerJ4:e2354.

x. Creswell, J. W. (2009). Research design: qualitative, quantitative and mixed methods, 3rd ed. Washington, DC: Sage Publication.

xi. Critchlow, R.; Plumptre, A. J.; Alidria, B.; Nsubuga, M.; Driciru, M.; Rwetsiba, A.; Wanyama, F.; and Beale, C. M.(2016). Improving law-enforcement effectiveness and efficiency in protected areas using ranger-collected monitoringdata. Conservation Letters

xii. DuffyR and HumphreysJ,(2014)Mapping donors: key areasfor tackling illegal wildlife trade (Africa and Asia), Evidenceon Demand, UK; F Booker and R Roe, First lineof defence? A review of evidence on the effectiveness ofengaging communities to tackle illegal wildlife trade, London:

xiii. Eliason, S. (2011) Policing Natural Resources: Issues in a Conservation Law Enforcement Agency, Professional Issues in Criminal Justice $\mathrm{Vol} 6(3 \& 4)$

xiv. Elkjaer, B. \& Simpson, B. (2011). 'Pragmatism: A lived and living philosophy. What can it offer to contemporary organization theory?' in Philosophy and Organization Theory. (Edited by Tsoukas, H. Chia, R.) Bradford: Emerald Publishing, pp. 55-84.

xv. Fornell, C., \& Larker, D. F. (1981). Evaluating Structural Equation Model with unobservable variables and Measurement errors. Vol. 18. N0.1. Pp 39-50.

xvi. Gavitt, J. D. (1989). Unlawful commercialization of wildlife parts. Transactions of the North American Wildlife \& Natural Resources Conference, 54, 314-323.

xvii. Handwerker, WP (2001) Quick Ethnography. Walnut Creek, CA: Alta Mira Press

xviii. Hooper, D., Coughlan, J. and Mullen, M. R. (2008). Structural Equation Modelling: Guidelines for Determining Model Fit. The Electronic Journal of Business Research Methods.Vol.6 No.1, pp 53 - 60

xix. Hox, J.J \& Bechger,T.M.(2042).An Introduction to Structural Equation Modeling. Family Science Review,Vol. 11,No.2,PP.354-373. 
xx. Kideghesho, J. (2016). The Elephant poaching crisis in Tanzania: a need to reverse the trend and the way forward. Journal of Tropical conservation Science Vol.9 (1), 369-388.

xxi. Lotter, W. and Clark. K (2016). Ruvuma Elephant Project, Progress Report for the period: 1 July 2013 to 31December 2013. Internal Report, PAMS Foundation, Tanzania.

xxii. Montana Fish, Wildlife, and Parks. (2011). Law enforcement reality show

xxiii. WARDENS" to debut on Outdoor Channel. Retrieved June 23, 2011, from http:/ / fwp.mt.gov/ news/ newsReleases/ headlines/nr_3932.html

xxiv. Mwalimu, S. (2016). Maghembe Suspends 11 Senior Official on Corruption. Citizen, p1. [http:/ / www.thecitizen.co.tz/ News/ Maghembe-suspends-11-senior--officials-on-corruption-charges/ 18403403133058-1 eyfne/ index.html] Accessed on 31/1/ 2016.

xxv. $\quad$ Musgrave, R. S., Parker, S., \& Wolok, M. (1993). The status of poaching in the United

xxvi. States: Are we protecting our wildlife? Natural Resources Journal, 33, 977-1014.

xxvii. Hall, D. L. (1992). Compliance: The mission of wildlife law enforcement. Proceedings of the Annual Conference of the Southeastern Association of Fish and Wildlife Agencies, 46, 532-542.

xxviii. Nguyen, T. H.; Sinha, A.; Gholami, S.; Plumptre, A.; Joppa,L.; Tambe, M.; Driciru, M.; Wanyama, F.; Rwetsiba, A.;Critchlow, R.; et al. (2016). Capture: A new predictive antipoachingtool for wildlife protection. 767-775. AAMAS

xxix. Nelson,F.et al., (2007) The Evolution and Reform of Tanzania Wildlife Management, 5(2) CONSERVATION AND SOCIETY 232,233-34,http:/ / www.conservationandsociety.org/ article.asp?issn=0972-4923;year= 2007; volume=5;issue $=2$;spage $=232$;epage $=261$; aulast=Nelson

xxx. Kideghesho, J.R. (2008), Who Pays for Wildlife Conservation in Tanzania and Who Benefits? (Conference Paper, available at [http:// dlc.dlib.indiana.edu/dlc/ bitstream/ handle/ 10535/ 587/ Kideghesho_102301.pdf? sequence=1]Accessed on 3/5/2018

xxxi. Rosen, G.E. \& Smith, K.F. (2010) Summarising the evidence on the international trade in illegal wildlife. EcoHealth, 7, 24- 32.

xxxii. Saunder, M., Lewis, P., \& Thornhill, A. (2014). Research methods for business students (4thed). London: Prentice Hall Financial Times. Harlow Pearson Educational Limited.

xxxiii. Steiger, J. H. (1990). Structural Model Evaluation and Modification. An interval Estimation Approach. Multivariate Behavior Research, Vol. 25 PP173-180

xxxiv. Schumacker, R. E., \& Lomax, R. G. (2004). A beginners Guide to Structural Equation Modeling 3rd Ed. Mawah, New Jersey: Lawrence Erlbuum Association.

xxxv. Watson, T. (2011). Ethnography, reality and truth: The vital need for studies of "how things work" in organizations and management', Journal of Management Studies, Vol. 48, No. 1, pp. 202-17.

xxxvi. Wasser, S. Clark, B., and C, Laurie. (2009). The Ivory Trail, Scientific American.301 Pp.68 - 76. Weber, M. (2001). The Protestant Ethic and the Spirit of Capitalism. London: Routledge

xxxvii. WWF. (2015). Human Elephant Conflict. [http:// wwf.panda.org/ what we do/ endangered species/ elephants/ ] Accessed on 7/6/ 2019. 


\section{Appendix}

\begin{tabular}{|c|c|c|}
\hline Category & Includes & Researcher noted \\
\hline $\begin{array}{c}\text { Physical } \\
\text { behaviour and } \\
\text { gestures }\end{array}$ & $\begin{array}{l}\text { Game Officers are largely } \\
\text { supervisors' daily wild } \\
\text { animals' conservations. } \\
\text { Through their interactions } \\
\text { with their joiners, they } \\
\text { arrange their daily } \\
\text { activities }\end{array}$ & $\begin{array}{c}\text { They were very good in terms of using their hands to insist } \\
\text { something, shows their fillings concerning how wild animals' } \\
\text { poaching is threatening their daily activities. }\end{array}$ \\
\hline $\begin{array}{l}\text { Physical Futures } \\
\text { on Research } \\
\text { areas }\end{array}$ & $\begin{array}{c}\text { Buildings, Camps sites, } \\
\text { Facilities }\end{array}$ & $\begin{array}{c}\text { Within Game Reserves, Game Controlled Areas and Anti-poaching } \\
\text { NGOs. Their equipped in terms with facilities heavy arms, cars but } \\
\text { with ought Antenna helping communication with those in patrol } \\
\text { and in office. Good offices. While in WMAs and Districts, do not } \\
\text { having facilities neither heavy arms but they have good offices. }\end{array}$ \\
\hline $\begin{array}{l}\text { Interaction } \\
\text { Between Wildlife } \\
\text { officers }\end{array}$ & $\begin{array}{l}\text { The interaction is based on } \\
\text { Officers and joiners. }\end{array}$ & The paramilitaries system of operations. Things are done by orders. \\
\hline Field Patrols & $\boldsymbol{\sim}$ With VGS & $\begin{array}{l}\text { VGSs with one Game warden from DGO office with short gun and } \\
\text { rifle, not well dressed, very committed to patrol and capture } 4 \\
\text { poachers with hippo meat, snares half land cruiser. }\end{array}$ \\
\hline $\begin{array}{l}\text { Trips on River } \\
\text { Ruvuma and } \\
\text { Ruhuji } \\
\text { Communities } \\
\text { living near } \\
\text { protected areas }\end{array}$ & $\begin{array}{l}\text { Visiting shoes of Rivers } \\
\text { Ruvuma and Ruhuji. } \\
\text { Attending political } \\
\text { campaigns, Funeral, } \\
\text { vijiweni discussion and } \\
\text { traditional pubs }\end{array}$ & $\begin{array}{l}\text { River Ruvuma crossing within Kimbanda, Mbarang'ndu, Kisungule } \\
\text { and Chingole WMAs. Number of unauthorised customs very busy } \\
\text { during night time people moving from Mozambique and Tanzania } \\
\text { and viceveser using Mitumbwi and Madema. Fishers with their } \\
\text { assistance known as makachera, difficulty to know whether these } \\
\text { are kachela or they have other activities. During night time stories } \\
\text { concerning fishing, forests products and wild animals poaching are } \\
\text { normal } \\
\text { While Ruhuji is water crossing Gessamasowa proposed Game } \\
\text { Reserve. Fishers and their kachelas are busy for fishing and selling } \\
\text { their fish. Blaming Kilombero hunting safaris investor for } \\
\text { prohibiting them fishing in his area, torturing those who found } \\
\text { fishing in his area by include removing their nails. } \\
\text { Both rivers are contain big and small ponds where are the home of } \\
\text { hippos, and crocodiles. Fishing is also activities going on there and } \\
\text { poachers are hiding within fishers. } \\
\text { There were much discussion concerning wildlife conservation and } \\
\text { the need to quit wildlife corridors because of lack of benefits. }\end{array}$ \\
\hline
\end{tabular}

Table 8:Participant Observation Checklists 